\title{
ERRATUM
}

B. I. Singh $\cdot$ S. Sinha $\cdot$ C. H. Brooks

\section{Bilateral posterior fracture dislocation of shoulder: a case report}

Published online: 16 June 2004

(C) Springer-Verlag 2004

\section{Eur J Orthop Surg Traumatol (2004)}

DOI 10.1007/s00590-004-0134-5

Fracture-luxation postérieure bilatérale de l'épaule

The initials of the first and third author and the details of the corresponding author were rendered incorrectly. The correct versions are given above.

The online version of the original article can be found at http:// dx.doi.org/10.1007/s00590-004-0134-5

B. I. Singh $(\bowtie) \cdot$ S. Sinha

Department of Trauma and Orthopaedics,

Kent and Canterbury Hospital, Ethelbert Road,

Canterbury, Kent, CT1 3NG, UK

E-mail: bisortho@doctors.org.uk

Tel.: + 44-1622-752640

Fax: + 44-20-88365458

C. H. Brooks

William Harvey Hospital,

Ashford, Kent, UK 